\title{
Hard Carbon Nanoparticles as High-capacity, High-stability Anodic Materials for Na-ion Batteries
}

Lifen Xiao ${ }^{\mathrm{a}, \mathrm{c}}$, Yuliang Cao ${ }^{\mathrm{b}, \mathrm{c}, *}$, Wesley A. Henderson ${ }^{\mathrm{c}}$, Maria L. Sushko ${ }^{\mathrm{c}}$, Yuyan Shao ${ }^{\mathrm{c}}$, Jie Xiao ${ }^{c}$, Wei Wang ${ }^{c}$, Mark H. Engelhard ${ }^{\mathrm{c}}$, Zimin Nie ${ }^{\mathrm{c}}$, Jun Liu ${ }^{\mathrm{c}, *}$

${ }^{a}$ College of Chemistry, Central China Normal University, Wuhan 430079, China

${ }^{\mathrm{b}}$ Hubei Key Laboratory of Electrochemical Power Sources, College of Chemistry and Molecular Science, Wuhan University, Wuhan, 430072, China

${ }^{\mathrm{c}}$ Pacific Northwest National Laboratory, Richland, Washington 99352, USA

*Corresponding author. E-mail address: ylcao@whu.edu.cn (Y. Cao), Jun.Liu@ pnnl.gov (J. Liu)

\section{Abstract}

Hard carbon nanoparticles (HCNP) were synthesized by the pyrolysis of a polyaniline precursor. The measured $\mathrm{Na}^{+}$cation diffusion coefficient $\left(10^{-13}-10^{-15} \mathrm{~cm}^{2} \mathrm{~s}^{-1}\right)$ in the HCNP obtained at $1150{ }^{\circ} \mathrm{C}$ is two orders of magnitude lower than that of $\mathrm{Li}^{+}$in graphite $\left(10^{-10}-10^{-13} \mathrm{~cm}^{2} \mathrm{~s}^{-1}\right)$, indicating that reducing the carbon particle size is very important for improving electrochemical performance. These measurements also enable a clear visualization of the stepwise reaction phases and rate changes which occur throughout the insertion/extraction processes in HCNP, The electrochemical measurements also show that the nano-sized $\mathrm{HCNP}$ obtained at $1150{ }^{\circ} \mathrm{C}$ exhibited higher practical capacity at voltages lower than $1.2 \mathrm{~V}$ (vs. $\mathrm{Na} / \mathrm{Na}^{+}$), as well as a prolonged cycling stability, which is attributed to an optimum spacing of $0.366 \mathrm{~nm}$ between the graphitic layers and the nano particular size resulting in a low-barrier $\mathrm{Na}^{+}$cation insertion. These results suggest that HCNP is a very promising high-capacity/stability anode for low cost sodium-ion batteries (SIBs). 


\section{Keywords}

Hard carbon; Ionic diffusion coefficient; Electrochemical impedance; Anode; Na-ion battery

\section{Introduction}

Large scale electrical energy storage (EES) requires the supporting battery systems not only to have a sufficient large storage capacity, but also to be cost-effective and ideally environmentally benign $[1,2]$. Utilization of Li-ion batteries (LIBs) for EES applications may be limited by a constraint on the global lithium availability [3]. In contrast, the high abundance and low environmental impact for sodium production make Na-ion batteries (SIBs) an attractive alternative [4]. The potential of room temperature rechargeable SIBs stimulated active research on the optimization of relevant cell chemistries through the exploration of the underlying factors limiting SIB performance. The more active chemical reactivity of $\mathrm{Na}$ metal and larger ionic diameter relative to $\mathrm{Li}$ metal have been identified as critical bottlenecks in SIB development. Controlling the Na reactivity requires strict control of both the moisture and oxygen content in the experimental environment. The $40 \%$ larger radius of $\mathrm{Na}^{+}$cations relative to $\mathrm{Li}^{+}$cations leads to higher $\mathrm{Na}^{+}$stability in the rigid lattices of electrode materials [5]. Consequently, the insertion and extraction of $\mathrm{Na}^{+}$cations can induce large stress changes in the host materials, causing rapid collapse of the lattice structures and therefore poor cycling stability. In addition, the diffusion of the large $\mathrm{Na}^{+}$cations within lattices is sluggish, resulting in 
poor electrochemical utilization and rate capability [6]. These factors have seriously hindered the development of SIBs over the last two decades.

One solution proposed recently for overcoming these intrinsic difficulties in the developing of efficient electrode materials for SIBs through the use of nanotechnology. For cathode active materials [3, 7-14], we [7] reported that a single crystalline $\mathrm{Na}_{4} \mathrm{Mn}_{9} \mathrm{O}_{18}$ nanowire could offer a highly reversible capacity of $128 \mathrm{mAh} \mathrm{g}^{-1}$ during the first charge/discharge cycle (at a $0.1 \mathrm{C}$ rate) and exhibited unprecedented cyclability (77\% capacity retention after 1000 cycles at a $0.5 \mathrm{C}$ rate). Yang's group [8] reported that a $\mathrm{Na}_{4} \mathrm{Fe}(\mathrm{CN})_{6} / \mathrm{C}$ nanocomposite electrode could deliver $90 \mathrm{mAh} \mathrm{g}^{-1}$ at a high potential of $3.4 \mathrm{~V}$ (vs. $\mathrm{Na} / \mathrm{Na}^{+}$) and exhibited an excellent cycling stability with $88 \%$ capacity retention after 500 cycles. Carbon-coated nanosized NASICON-type $\mathrm{Na}_{3} \mathrm{~V}_{2}\left(\mathrm{PO}_{4}\right)_{3}$ was found to exhibit an ultrafast rate capability $[9,10,15,16]$. According to Fang et al. [15], the $\mathrm{Na}_{3} \mathrm{~V}_{2}\left(\mathrm{PO}_{4}\right)_{3} / \mathrm{C}$ composite could exhibit superior electrochemical performance of both ultra-high rate capability (38 $\mathrm{mAh} \mathrm{g}^{-1}$ at 500C) and ultra-long cycling lifespan (20000 cycles at 30C), which exceeds most of the electrodes used in rechargeable batteries.

For anode active materials, Wang et al. [17] reported a layered $\mathrm{P} 2-\mathrm{Na}_{0.66}\left[\mathrm{Li}_{0.22} \mathrm{Ti}_{0.78}\right] \mathrm{O}_{2}$ material which exhibited zero-strain characteristics during $\mathrm{Na}^{+}$cation insertion/extraction. Wu et al. [18] reported a highly stable Sb-C nanofiber alloy anode which had a large initial reversible capacity of $504 \mathrm{mAh} \mathrm{g}^{-1}$ at a $200 \mathrm{~mA} \mathrm{~g}^{-1}$ rate and a $90 \%$ capacity retention after 400 cycles. Qu et al. [19] reported a $\mathrm{SnS}_{2}-\mathrm{RGO}$ composite anode which demonstrated a superior reversible capacity of $630 \mathrm{mAh} \mathrm{g}^{-1}$ at a $0.2 \mathrm{~A} \mathrm{~g}^{-1}$ rate resulting from a combined electrochemical conversion and alloying/dealloying mechanism, and good cyclability (500 $\mathrm{mAh} \mathrm{g}^{-1}$ at a $1 \mathrm{~A} \mathrm{~g}^{-1}$ rate for 400 cycles). While offering excellent 
electrochemical performance, these materials are expensive for practical applications. In contrast, carbonaceous materials are more economically viable and abundant [20, 21]. Several hard carbons have been reported to have a favorable $\mathrm{Na}^{+}$cation storage capacity (250-300 $\left.\mathrm{mAh} \mathrm{g}^{-1}\right)$ and good rate capability [22-26]. For instance, Ding et al. [25] reported a highly ordered pseudographitic carbon with an intergraphene spacing of 0.388 $\mathrm{nm}$ derived from a biomass precursor which exhibited highly reversible capacity of 298 $\mathrm{mAh} \mathrm{g}^{-1}$ (after 10 cycles at $50 \mathrm{~mA} \mathrm{~g}^{-1}$ ) and a high rate capability (66 $\mathrm{mAh} \mathrm{g}^{-1}$ at a $5 \mathrm{~A} \mathrm{~g}^{-1}$ rate). However, achieving a prolonged cycling stability for hard carbon anodes for $\mathrm{Na}^{+}$ storage, in particular for high charge-discharge rates, has remained a difficult challenge [27]. Through a combined experimental and theoretical study, we have demonstrated facile $\mathrm{Na}^{+}$cation uptake and release in a carbon with a spacing of greater than $0.37 \mathrm{~nm}$ between the graphitic sheets [23]. In that study, hollow carbon nanowires synthesized by the direct pyrolyzation of polyaniline showed an initial reversible capacity of $251 \mathrm{mAh} \mathrm{g}^{-}$ ${ }^{1}$ and capacity retention of $82.2 \%$ at a $50 \mathrm{~mA} \mathrm{~g}^{-1}$ rate after 400 cycles. Nevertheless, a further optimization of the synthesis procedure through a detailed study of the influence of the structure of the polyaniline precursor and the carbonization temperature on the $\mathrm{Na}^{+}$ cation storage properties is desired.

Herein, we report the refined method for fabrication of hard carbon nanoparticles (HCNPs) from polyaniline. The spectroscopic characterization show that HCNPs obtained at $1150{ }^{\circ} \mathrm{C}$ have the largest interlayer distance between the graphite layers and consist of large graphitic clusters, thus displaying an optimum electrochemical performance. The measurements of the $\mathrm{Na}^{+}$cations diffusion variation throughout the insertion/extraction processes in HCNP by electrochemical impedance spectroscopy (EIS) 
show lower $\mathrm{Na}^{+}$diffusion rate than that of $\mathrm{Li}^{+}$in graphite highlighting the importance of nanostructuring.

\section{Materials and methods}

\section{Material preparation}

Polyaniline (PANI) was synthesized by a chemical oxidative method: $0.9 \mathrm{~mL}$ of aniline was dissolved in $80 \mathrm{~mL}$ of $1.5 \mathrm{~mol} \mathrm{~L}{ }^{-1} \mathrm{HCl}$ by stirring. $2.28 \mathrm{~g}$ of $\left(\mathrm{NH}_{4}\right)_{2} \mathrm{~S}_{2} \mathrm{O}_{8}$ was dissolved in $20 \mathrm{~mL}$ of deionized water and then quickly added to the aniline solution. The mixture was stirred at room temperature for $12 \mathrm{~h}$. The resulting PANI solid product was washed with deionized water until the filtrate became both colorless and $\mathrm{pH}$ neutral and the solid was then dried at $50{ }^{\circ} \mathrm{C}$ overnight. Finally, the PANI was calcinated at 800 , 1000 and $1150{ }^{\circ} \mathrm{C}$ for $6 \mathrm{~h}$ in an $\mathrm{N}_{2}$ atmosphere to obtain the target hard carbon nanoparticles (HCNP-800, HCNP-1000 and HCNP-1150, respectively).

\section{Structural characterization}

Scanning electron microscopy (SEM), transmission electron microscopy (TEM), and high-resolution TEM (HRTEM) experiments were performed on a FEI Helios Nanolab dual-beam, focused ion beam/scanning electron microscope (FIB/SEM) and a JEOL2010 high-resolution electron microscope. X-ray diffraction (XRD) measurements were conducted on a Philips Xpert X-ray diffractometer using $\mathrm{Cu} \mathrm{K \alpha}$ radiation $(\lambda=1.54 \AA)$. 
$\mathrm{N}_{2}$ adsorption/desorption isotherms for surface area and pore analyses were measured with a Quantachrome autosorb, automated gas sorption system.

\section{Electrochemical measurements}

The HCNP-based anodes were prepared by mixing $80 \mathrm{wt} \%$ HCNP powder, $10 \mathrm{wt} \%$ Super P carbon black, and 10 wt\% polyvinylidene difluoride (PVDF) dissolved in $\mathrm{N}$ methyl-2-pyrrolidone (NMP) to form slurry. The slurry was pasted on $\mathrm{Cu}$ foil current collectors and the NMP solvent was evaporated. Electrochemical tests were performed with 2035 coin cells having Na metal as both the counter- and reference electrodes. The electrolyte was $1 \mathrm{M} \mathrm{NaClO}_{4}$ dissolved in a mixture of ethylene carbonate (EC) and dimethyl carbonate (DMC) (1:2 by wt.), and the separator was a microporous membrane (Celgard 2135). The cells were assembled in an Ar-filled glove box. The galvanostatic charge-discharge tests were conducted at a voltage interval of $0-1.2 \mathrm{~V}\left(\mathrm{vs} . \mathrm{Na} / \mathrm{Na}^{+}\right)$with a BT-2000 Arbin battery testing system. Cyclic voltammetry (CV) measurements were carried out at a scan rate of $0.1 \mathrm{mV} \mathrm{s}^{-1}$ using a SI 1287 electrochemical interface (Solartron). To obtain the diffusion coefficient of the $\mathrm{Na}^{+}$cations within the hard carbon anodes, EIS measurements were conducted with a frequency response analyzer (Solartron, SI 1260) in the frequency range $100 \mathrm{kHz}$ to $3 \mathrm{mHz}$ with an $\mathrm{AC}$ signal amplitude of $10 \mathrm{mV}$. The cells for the EIS measurements were cycled galvanostatically twice and were charged (or discharged) at a $30 \mathrm{~mA} \mathrm{~g}^{-1}$ rate for $1 \mathrm{~h}$. After the cells relaxed to equilibrium potentials (i.e., open circuit voltage (OCV) condition) for $3 \mathrm{~h}$, the impedance response was measured. 


\section{Results and discussion}

The polyaniline precursor was readily synthesized by a chemical oxidative method (see experimental section). It follows from the SEM data that the precursor has a uniform nanoparticle morphology with particles diameters around 70-100 nm (Fig. 1a). After being pyrolyzed at $1150{ }^{\circ} \mathrm{C}$ for $6 \mathrm{~h}$ in an $\mathrm{N}_{2}$ atmosphere, the resulting hard carbon material (HCNP-1150) shows no obvious morphological modifications relative to its precursor (Fig. 1b and c). The HRTEM image of an individual carbon nanoparticle shows that it has regions of stacked graphite sheets, as well as amorphous regions (Fig. 1d). The average distance between the graphite sheets is about $0.37 \mathrm{~nm}$. Considerable numbers of nanovoids, presumably formed by the gas escape during the pyrolyzation process, are evident in the amorphous regions.

Fig. 2a compares the XRD patterns of the pristine polyaniline, HCNP-800, -1000 and 1150 materials. The pristine PANI exhibits a broad peak around $2 \theta=25^{\circ}$, indicating an amorphous morphology $[23,28,29]$. All of the carbon products, in contrast, have two broad peaks at $25^{\circ}$ and $44^{\circ}$, corresponding to the (002) diffraction of the graphitic layerby-layer structure and the (101) diffraction of graphite, respectively. Notably, the locations of the (002) peaks for HCNP-800, $-1000,-1150$ are at 25.39, 25.03 and $24.34^{\circ}$, respectively, indicating that a slightly negative shift occurs with increasing pyrolysis temperature. According to the positions of the (002) peaks, the spacing between the stacked graphite sheets in HCNP-800, $-1000,-1150$ are calculated to be $0.350,0.355$ and $0.366 \mathrm{~nm}$, respectively. The value for HCNP-1150 is in good agreement with that from 
the HRTEM data in Fig. 1d. At first glance, the increase in the spacing between the graphite sheets with increasing processing temperature may seem unusual, but this may originate from nitrogen atom intercalation in-between the graphite sheets during the pyrolyzation at elevated temperature, as reported by other authors $[30,31]$ and as schematically shown in Fig. 2b. The elemental analysis demonstrates that the residual contents of nitrogen atoms in the resulting carbon materials gradually decrease with increased processing temperature (Tab. 1), suggesting that nitrogen atoms are removed from the graphite sheets. It is possible that part of the dissociated nitrogen atoms can reside in between the graphite sheets so as to expand their spacings. The presence of nitrogen atoms in-between the graphite layers can be confirmed by XPS measurements. N1s XPS data for the pristine PANI and the pyrolyzed carbon obtained at different temperatures are shown in Fig. 3 and listed in Tab. 1. The N1s peak of the pristine PANI (Fig. 3a) can be deconvoluted into two peaks arising from nitrogen in two different environments. The peak positioned at lower binding energy $(399.3 \mathrm{eV})$ is associated with the uncharged amine sites, while the other peak located at a higher binding energy (400.3 $\mathrm{eV}$ ) is attributed to imine cationic radicals [32]. The XPS data in the N1s region for the pyrolyzed carbon are different (Fig. 3b, c and d). The spectrum for HCNP-800 splits into two peaks and envelops the contributions from three components after fitting (Fig. 3b). The peak centered at $398.2 \mathrm{eV}$ may be attributed to pyridinic-nitrogen $(\mathrm{N}-6)$ in the phenazine heterocyclic structure formed in the early stage of carbonization. The second peak positioned at $400.8 \mathrm{eV}$ may be assigned to the quaternary (N-Q) nitrogen species doped at the edges of or in-between the graphite layers [33]. The last peak located at the highest binding energy (401.4 eV) implies a more positively charged nitrogen site than 
for the imine cationic radicals in pristine PANI (Fig. 3a), which possibly results from the $\mathrm{N}-\mathrm{O}$ binding in the surface layer due to air exposure [34]. The fitted peak around $398 \mathrm{eV}$ decreases in intensity with an elevation in pyrolysis temperature and disappears completely at $1150{ }^{\circ} \mathrm{C}$, suggesting an enhanced denitrification and graphitization. However, it is possible that a small portion of the nitrogen groups removed from the condensed carbon rings may reside in-between the graphite layers (as shown in Fig. 2b), resulting in increased interlayer distances, as can be corroborated from the remaining strong peak around $401 \mathrm{eV}$. The shift towards higher binding energy for the peaks assigned to the N-Q ( 401 eV) and N-O ( 402 eV) binding implies that a slight change in the chemical environment occurs with increased temperature.

Electrochemical impedance spectroscopy (EIS) was performed to understand the $\mathrm{Na}^{+}$ cation diffusion properties within HCNP-1150 electrode. Fig. $4 \mathrm{a}$ and $\mathrm{b}$ show the experimental impedance spectra measured at various potentials during discharge and charge, respectively. These data show that the electrochemical resistance of the electrode tends to decrease with the depth of discharge (Fig. 4a), while it increases with the depth of charge (Fig. 4b). This phenomenon probably arises from the increased electric conductivity of the sodium-carbon material with sodiation process, which facilitates the electrochemical reaction kinetics. Fig. 4c shows a typical Nyquist plot for the HCNP1150 electrode obtained during charging at $0.11 \mathrm{~V}$. It displays two depressed semicircles in the high and medium frequency regions and a monotonic dependence in the low frequency region. It can be presumed that the semicircles in the high and medium frequency regions are attributed to the surface film resistance between the electrode and 
electrolyte and to the charge transfer resistance, respectively, while the linear region corresponds to the Warburg diffusion of $\mathrm{Na}^{+}$cations in the bulk carbon.

Fig. $4 d$ shows a linear relationship between the $Z^{\prime}\left(-Z^{\prime \prime}\right)$ and the square root of the frequency $\left(\omega^{-1 / 2}\right)$ in the low frequency Warburg region of Fig. 4 c. Since the $\mathrm{Na}^{+}$cation diffusion coefficient $\left(D_{\mathrm{Na}}{ }^{+}\right)$can be written as [7, 35-37]:

$$
D_{N a^{+}}=1 / 2\left[\left(\frac{V_{m}}{F S A_{w}}\right) \frac{d E}{d x}\right]
$$

based upon the EIS response, where $V_{\mathrm{m}}$ is the molar volume of carbon $\left(\mathrm{C}_{6}\right)\left(6 \times 5.75 \mathrm{~cm}^{3}\right.$ $\left.\mathrm{mol}^{-1}\right)$ calculated using the XRD density $\left(2.086 \mathrm{~g} \mathrm{~cm}^{-3}\right.$; hexagonal crystal system with lattice vectors $a=2.45 \AA, c=7.32 \AA) ; F$ is the Faraday constant $\left(96,486 \mathrm{C} \mathrm{mol}^{-1}\right) ; S$ is the contact area between electrolyte and electrode material (approximately taken as the BET surface area of HCNP-1150 equal to $23.5 \mathrm{~m}^{2} \mathrm{~g}^{-1}$ ); $A_{\mathrm{w}}$ is the Warburg coefficient, which was determined as the average values of the slope from the $Z^{\prime}$ and $-Z^{\prime \prime}$ vs. $\omega^{-1 / 2}$ plots ( $\omega$ is the angular frequency) shown in Fig. $4 \mathrm{~d}$; and $(d E / d x)$ is the differential of the galvanostatic titration curve. $D_{\mathrm{Na}+}$ at different $\mathrm{OCV}$ values during charge and discharge can be calculated using the Eq. 1 (Fig. 5). $D_{\mathrm{Na}}$ demonstrates a similar variation with OCV during the $\mathrm{Na}^{+}$cation insertion and extraction processes and exhibits a broad peak around 0.6 and $0.1 \mathrm{~V}$ followed by sharp decrease below $0.1 \mathrm{~V}$. This $\log D$ vs. $E$ curve at low potential region is very similar to that observed during $\mathrm{Li}^{+}$cation diffusion in graphite, $[38,39]$ suggesting a phase transition process from graphitic carbon to $\mathrm{NaC}_{\mathrm{x}}$ structure (that is, forming sodium-graphite intercalation compounds (Na-GICs). The slight increase of $D_{\mathrm{Na}+}$ nearby $0 \mathrm{~V}$ is probably due to the highly attractive interactions between the inserted $\mathrm{Na}$ ions in the single-phase Na-GICs, similar to $\mathrm{Li}^{+}$cation insertion in graphite near $0 \mathrm{~V}$ as reported in previous literatures. [32, 40, 41] In the voltage range 
of $0-1.0 \mathrm{~V}, D_{\mathrm{Na}+}$ is equal to $10^{-13}-10^{-15} \mathrm{~cm}^{2} \mathrm{~s}^{-1}$, which is two orders of magnitude lower than that of $D_{\mathrm{Li}+}$ in graphite $\left(10^{-10}-10^{-13} \mathrm{~cm}^{2} \mathrm{~s}^{-1}\right)$, reflecting, among other factors, the larger diameter of the $\mathrm{Na}^{+}$cations.

Fig. 6a displays the initial discharge-charge profiles of the HCNP electrodes. The electrodes were tested in the potential range between $0-1.2 \mathrm{~V}\left(\mathrm{vs} . \mathrm{Na} / \mathrm{Na}^{+}\right)$at a constant current rate of $50 \mathrm{~mA} \mathrm{~g}^{-1}(0.2 \mathrm{C})$. These data demonstrate that the HCNP-800, -1000 and -1150 electrodes have an uptake discharge capacity of 628,556 and $523 \mathrm{mAh} \mathrm{g}^{-1}$ and offer a reversible charge capacity of 230,266 and $270 \mathrm{mAh} \mathrm{g}^{-1}$, respectively. There is a clear trend of enhanced electrochemical performance of the HCNPs manifested by the decrease in the initial irreversible capacity loss and the increase in the reversible capacity with the elevation in the heat treatment temperature. It should be noted that the improvement is not very significant for the 1000 to $1150{ }^{\circ} \mathrm{C}$ temperature range. All of the HCNPs undergo irreversible reactions in the potential range of $1.5-0.4 \mathrm{~V}$ (vs. $\mathrm{Na} / \mathrm{Na}^{+}$) giving rise to a notable irreversible capacity loss. Similar to the irreversible reactions which occur for LIB electrodes, this irreversible capacity loss is mainly due to decomposition of the electrolyte components on the active sites on the electrode surface and the formation of a solid-electrolyte interphase (SEI) film on the carbon surface. Furthermore, it can be observed that the discharge curves have two distinct regions: a relatively flat plateau around $0.1 \mathrm{~V}$ and a sloping discharge above $0.2 \mathrm{~V}$ (Fig. 6a). The plateau at lower potential is attributed to the $\mathrm{Na}^{+}$cation insertion-extraction in the interlayers of the graphite sheets similar to that for $\mathrm{Li}^{+}$cation insertion-extraction in graphite. The slope in $1.2-0.2 \mathrm{~V}$ voltage range may be attributable to charge transfer on the surface of the small graphitic clusters, in other words, to the adsorption of $\mathrm{Na}^{+}$ions on 
the surficial active sites of the carbon. The charge-discharge curves are in good agreement with those for hollow nanowire shaped carbon reported previously by our group [23]. Another phenomenon that should be noted is that the potential plateau elongates with increasing HCNP carbonization temperature (Fig. 6a), suggesting that an increased fraction of the charge capacity is due to $\mathrm{Na}^{+}$cation insertion/extraction between the graphitic sheets. This phenomenon was also observed in pseudographitic carbon nanosheets [25]. As the carbonization temperature increases, the ordered graphitic domains in the carbon will grow, thus providing more $\mathrm{Na}^{+}$cation insertion sites. Our previous theoretical simulation of the energy cost for $\mathrm{Na}^{+}$cation insertion into carbon indicates that the enlargement of the spacing between the graphitic layers is beneficial for $\mathrm{Na}^{+}$cation insertion. Thus, $\mathrm{Na}^{+}$cation insertion into the graphitic nanocrystallites is facilitated in HCNP-1150 which has the largest spacing between the graphitic layers. It is noteworthy that the charge cutoff voltage for the HCNP electrode is set to $1.2 \mathrm{~V}$, which means that the capacity achieved is in the optimum voltage range for full SIBs. Therefore, the useful capacity of the HCNP active material is one of the highest reported to date. Although some disordered hard carbon might have high Na storage capacity as reported higher than $300 \mathrm{mAh} \mathrm{g}^{-1}$ [42], they display a slop potential curve at a wide potential range up to $3 \mathrm{~V}$ similar to the insertion of $\mathrm{Li}$ into disordered carbon. In fact, we need anode materials with low average potential to improve the energy density of batteries. So, hard carbons with high graphitic degree and large lattice distance are more practical due to the increased reversible Na storage capacity at the low potential region (Fig 6a).

Fig. $6 \mathrm{~b}$ shows the CV curves for the HCNP-1150 electrode cycled at a scan rate of 0.1 $\mathrm{mV} \mathrm{s}^{-1}$. Two small reduction peaks at 1.1 and $0.5 \mathrm{~V}\left(\mathrm{vs} . \mathrm{Na} / \mathrm{Na}^{+}\right)$appear only in the first 
cathodic scan suggesting that irreversible reactions occur. Moreover, a pair of sharp redox peaks in the low potential region is related to the reversible insertion/extraction of $\mathrm{Na}^{+}$cations between the graphitic layers, and a pair of weak humps at $0.2-1.0 \mathrm{~V}$ are attributed to the charge transfer occurring on the surfaces of the small graphitic clusters. In the subsequent cycles, the CV curves almost overlap, illustrating a high $\mathrm{Na}^{+}$cation insertion/extraction reversibility. Interestingly, the shape of the CV curves correlate well with the variation in the $\mathrm{Na}^{+}$cation diffusion coefficient shown in Fig. 5, further highlighting the differences in $\mathrm{Na}^{+}$cation diffusion mechanism in different voltage regimes.

Fig. $6 \mathrm{c}$ shows the cycling performance of the HCNP electrodes at a constant current density of $50 \mathrm{~mA} \mathrm{~g}^{-1}$. The HCNP-800, -1000 and -1150 electrodes exhibited a capacity loss of $0.56 \%, 0.17 \%$ and $0.05 \%$ per cycle, respectively. HCNP- 1150 has the highest cyclability, as well as reversible capacity, due to the considerable fraction of crystalline graphite clusters and appropriate interlayer spacing for low-barrier $\mathrm{Na}^{+}$cation insertion. Even after 500 cycles, the HCNP-1150 electrode still maintains a high reversible capacity of $207 \mathrm{mAh} \mathrm{g}^{-1}$, corresponding to a 77\% capacity retention. However, the low initial coulombic efficiency of $51.6 \%$ is still an issue that needs to be addressed prior to practical applications. Although the surface area of HCNP-1150 is $30 \%$ smaller than that of our previously reported hollow carbon nanowires [23], the initial coulombic efficiency only shows a $1.2 \%$ improvement, indicating other factors, such as the modification of the electrolyte, are responsible for this effect. Nevertheless, after the initial cycle, the coulombic efficiency of the electrode increases to $\sim 96 \%$ at the fifth cycle and then to approximately $\sim 99 \%$ after 10 cycles. 
Fig. 6d displays the cycling rate behavior of the HCNP-1150 electrode. The electrode delivers reversible capacities of $275,266,236,181,72$ and $45 \mathrm{mAh} \mathrm{g}^{-1}$ at a current density of 25 (0.1C), 50 (0.2 C), 125 (0.5 C), 250 (1 C), 1250 (5 C) and 2500 (10 C) mA

$\mathrm{g}^{-1}$, respectively. When the rate is reset to $50 \mathrm{~mA} \mathrm{~g}^{-1}$, the electrode capacity recovers to $260 \mathrm{mAh} \mathrm{g}^{-1}$ (i.e., retains $82 \%$ of the original capacity) after 200 cycles, which indicates both a high rate capability and excellent tolerance of the material to rapid $\mathrm{Na}^{+}$cation insertion and extraction. However, the rate capability of the present HCNP-1150 is inferior to that of the hollow carbon nanowires reported previously [23], probably because of slower electron transfer.

\section{Conclusions}

Hard carbon nanoparticles were prepared by pyrolyzing a polyaniline precursor. The carbon material obtained at $1150{ }^{\circ} \mathrm{C}$ shows an interlayer distance of $0.366 \mathrm{~nm}$ between the graphitic layers, sufficient for low-barrier $\mathrm{Na}^{+}$cation insertion and extraction. Such an interlayer distance is attributed to a residual nitrogen atom incorporation in-between the graphitic layers. The $\mathrm{Na}^{+}$cations diffusion variation throughout the insertion/extraction processes in HCNP was first measured, which provides helpful insight into the stepwise $\mathrm{Na}^{+}$cation insertion/extraction phases and rates in hard carbon materials. The HCNP1150 electrode exhibits a high initial $\mathrm{Na}^{+}$cation storage capacity $\left(270 \mathrm{mAh} \mathrm{g}^{-1}\right.$ at a 50 $\mathrm{mA} \mathrm{g}^{-1}$ rate in the voltage range of $0-1.2 \mathrm{~V}$ ), good cycling stability (77\% capacity retention over 500 cycles), and high rate capability (45 $\mathrm{mAh} \mathrm{g}^{-1}$ at $\left.2500 \mathrm{~mA} \mathrm{~g}^{-1}\right)$. Significantly, the work presented here provides a new method for the synthesis of promising anode material for cost-efficient SIBs. 


\section{Acknowledgements}

This research was supported by the U.S. Department of Energy (DOE), Office of Basic Energy Sciences, Division of Materials Sciences and Engineering under Award KC020105-FWP12152. Lifen Xiao would like to acknowledge the support by the National Natural Science Foundation of China (no. 21273090). Yuliang Cao would like to acknowledge the support by the National Natural Science Foundation of China (No. 21373155) and Program for New Century Excellent Talents in University (NCET-120419) and Hubei National Funds for Distinguished Young Scientists (2014CFA038). The

TEM and XPS measurements were conducted at the Environmental and Molecular Sciences Laboratory (EMSL), a national scientific user facility sponsored by the Department of Energy's Office of Biological and Environmental Research and located at Pacific Northwest National Laboratory (PNNL).

\section{References}

[1] Z. Yang, J. Zhang, M.C.W. Kintner-Meyer, X. Lu, D. Choi, J.P. Lemmon, J. Liu, Chem. Rev. 111 (2011) 3577.

[2] J. Liu, Adv. Funct. Mater. 23 (2013) 924.

[3] J.-M. Tarascon, Nat. Chem. 2 (2010) 510.

[4] V. Palomares, P. Serras, I. Villaluenga, K.B. Hueso, J. Carretero-González, T. Rojo, Energy Environ. Sci. 5 (2012) 5884.

[5] M.D. Slater, D. Kim, E. Lee, C.S. Johnson, Adv. Funct. Mater. 23 ((2013) 947.

[6] S.-W. Kim, D.-H. Seo, X. Ma, G. Ceder, K. Kang, Adv. Energy Mater. 2 (2012) 710.

[7] Y. Cao, L. Xiao, W. Wang, D. Choi, Z. Nie, J. Yu, L.V. Saraf, Z. Yang, J. Liu, Advanced. mater. 23 (2011) 3155.

[8] J. Qian, M. Zhou, Y. Cao, X. Ai, H. Yang, Adv. Energy Mater. 2 (2012) 410.

[9] C. Zhu, K. Song, P.A.V. Aken, J. Maier, Y. Yu, Nano Lett. 14 (2014) 2175.

[10] K. Saravanan, C.W. Mason, A. Rudola, K.H. Wong, P. Balaya, Adv. Energy Mater. 3 (2013) 444. 
[11] D. Yuan, X. Hu, J. Qian, F. Pei, F. Wu, R. Mao, X. Ai, H. Yang, Y. Cao, Electrochim. Acta 116 (2014) 300.

[12] D. Kim, E. Lee, M. Slater, W. Lu, S. Rood, C.S. Johnson, Electrochem. Commun. 18 (2012) 66.

[13] D. Billaud, F.X. Henry, P. Willmann, Mater. Res. Bull. 28 (1993) 477.

[14] D. Yuan, W. He, F. Pei, F. Wu, Y. Wu, J. Qian, Y. Cao, X. Ai, H. Yang, J. Mater. Chem. A 1 (2013) 3895.

[15] Y. Fang, L. Xiao, X. Ai, Y. Cao, H. Yang, Adv. Mater. DOI: 10.1002/adma.201502018 (2015).

[16] C. Zhu, K. Song, P.A. van Aken, J. Maier, Y. Yu, Nano Letters 14 (2014) 21752180.

[17] Y. Wang, X. Yu, S. Xu, J. Bai, R. Xiao, Y.-S. Hu, H. Li, X.-Q. Yang, L. Chen, X. Huang, Nat. Commun. 4 (2013) 2365.

[18] L. Wu, X. Hu, J. Qian, F. Pei, F. Wu, R. Mao, X. Ai, H. Yang, Y. Cao, Energy Environ. Sci. 7 (2014) 323.

[19] B. Qu, C. Ma, G. Ji, C. Xu, J. Xu, Y.S. Meng, T. Wang, J.Y. Lee, Adv. Mater. 26 (2014) 3854.

[20] S. Wenzel, J.J. T. Hara, P. Adelhelm, Energy Environ. Sci. 4 (2011) 3342.

[21] S. Komaba, W. Murata, T. Ishikawa, N. Yabuuchi, T. Ozeki, T. Nakayama, A. Ogata, K. Gotoh, K. Fujiwara, Adv. Funct. Mater. 21 (2011) 3859.

[22] K. Tang, L. Fu, R.J. White, L. Yu, M.-M. Titirici, M. Antonietti, J. Maier, Adv. Energy Mater. 2 (2012) 873.

[23] Y. Cao, L. Xiao, M.L. Sushko, W. Wang, B. Schwenzer, J. Xiao, Z. Nie, L.V. Saraf, Z. Yang, J. Liu, Nano Lett. 12 (2012) 3783.

[24] H. Wang, Z. Wu, F. Meng, D. Ma, X. Huang, L. Wang, X. Zhang, ChemSusChem 6 (2013) 56.

[25] J. Ding, H. Wang, Z. Li, A. Kohandehghan, K. Cui, Z. Xu, B. Zahiri, X. Tan, E.M. Lotfabad, B.C. Olsen, D. Mitlin, ACS Nano 7 (2013) 11004.

[26] L. Fu, K. Tang, K. Song, P.A. van Aken, Y. Yu, J. Maier, Nanoscale 6 (2014) 13841389.

[27] W. Luo, J. Schardt, C. Bommier, B. Wang, J. Razink, J. Simonsen, X. Ji, J. Mater. Chem. A 1 (2013) 10662.

[28] G.-Y. Zhao, H.-L. Li, Microporous Mesoporous Mater. 110 (2008) 590.

[29] L. Xiao, Y. Cao, J. Xiao, B. Schwenzer, M.H. Engelhard, L.V. Saraf, Z. Nie, G.J. Exarhos, J. Liu, Adv. Mater. 24 (2012) 1176.

[30] R. Mathewa, B.R. Mattesb, M.P. Espea, Synth. Met. 131 (2002) 141.

[31] M. Trchova, P. Matejka, J. Brodinova, A. Kalendova, J. Prokes, J. Stejskal, Polym. Degrad. Stab. 91 (2006) 114.

[32] J. Yue, A.J. Epstein, Macromolecules 24 (1991) 4441.

[33] Z. Lei, M. Zhao, L. Dang, L. An, M. Lu, A.-Y. Lo, N. Yu, S.-B. Liu, J. Mater. Chem. 19 (2009) 5985.

[34] L. Lin, H. Niu, M. Zhang, W. Song, Z. Wang, X. Bai, Appl. Surf. Sci. 254 (2008) 7250.

[35] C. He, I.D. Raistrick, R.A. Huggins, J. Electrochem. Soc. 127 (1980) 343.

[36] M.I.O. Yamada, M. Morita, Electrochim. Acta 45 (2000) 2197.

[37] K.M. Shaju, G.V.S. Rao, B.V.R. Chowdari, Electrochim. Acta 48 (2003) 2691. 
[38] M. Nishizawa, R. Hashitani, T. Itoh, T. Matsue, I. Uchida, Electrochem. Solid-State Lett. 1 (1998) 10.

[39] A. Funabiki, M. Inaba, Z. Ogumi, J. Electrochem. Soc. 145 (1998) 172.

[40] B. Markovsky, M.D. Levi, D. Aurbach, Electrochim. Acta 43 (1998) 2287.

[41] M.D. Levi, E. Markevich, D. Aurbach, Electrochim. Acta 51 (2005) 98.

[42] L. Qie, W. Chen, X. Xiong, C. Hu, F. Zou, P. Hu, Y. Huang, Adv. Sci. DOI: 10.1002/advs.201500195 (2015). 
Table 1 Results of the BET data, elemental compositions and binding energies of N1s component peaks for PANI and HCNPs.

\begin{tabular}{cccccccccc}
\hline & \multirow{2}{*}{ BET/m $\mathrm{m}^{2} \mathrm{~g}^{-1}$} & \multicolumn{2}{c}{ Pore } & \multicolumn{3}{c}{ Elemental analysis / wt.\% } & \multicolumn{4}{c}{ XPS analysis / eV } \\
& & Volume/cc g & $\mathrm{C}$ & $\mathrm{N}$ & $\mathrm{H}$ & Component 1 & Component 2 & Component 3 \\
\hline PANI & 30.3 & 0.338 & 60.07 & 11.1 & 5.1 & 399.3 & 400.3 & -- \\
HCNP-800 & 18.5 & 0.156 & 78.36 & 1.4 & 6.6 & 398.2 & 400.8 & 401.4 \\
HCNP-1000 & 21.0 & 0.151 & 82.95 & 1.2 & 2.6 & 398.1 & 400.9 & 401.8 \\
HCNP-1150 & 23.5 & 0.139 & 85.60 & 1.0 & 1.7 & -- & 401.1 & 402.3 \\
\hline
\end{tabular}




\section{Figure captions:}

Fig. 1 (a, b) SEM images of PANI and HCNP-1150. (c) TEM image of HCNP-1150. (d) High-Resolution TEM (HRTEM) image of HCNP-1150.

Fig. 2 (a) XRD patterns of polyaniline and the HCNPs pyrolyzed at different temperatures. (b) Schematic illustration of the formation and structural characteristics of HCNP.

Fig. 3 N1s XPS spectra of (a) pristine PANI, (b) HCNP-800, (c) HCNP-1000 and (d) HCNP-1150.

Fig. 4 EIS results for HCNP-1150. Nyquist plots at various potentials during (a) discharge and (b) charge. (c) Nyquist plot and fitting curve using the equivalent circuit (inset in Fig. 4c). (d) $Z^{\prime}$ or $-Z^{\prime}$ vs. $\omega^{-1 / 2}$ plot at $0.11 \mathrm{~V}$ during charge.

Fig. 5 Logarithm diffusion coefficient $(\log D)$ vs. OCV plots at various potentials for HCNP-1150.

Fig. 6 Electrochemical characterization of the HCNPs as anode material for SIBs. (a) First discharge/charge profiles of HCNPs pyrolyzed at different temperatures between 0 and $1.2 \mathrm{~V}$ at a current density of $50 \mathrm{~mA} \mathrm{~g}^{-1}(0.2 \mathrm{C})$. (b) $\mathrm{CV}$ curves of the HCNP-1150 electrode between $0-2.5 \mathrm{~V}\left(\mathrm{vs} . \mathrm{Na} / \mathrm{Na}^{+}\right)$at a potential sweep rate of $0.1 \mathrm{mV} \mathrm{s}^{-1}$. (c) Cycling performance of the HCNP electrodes at a current density of $50 \mathrm{~mA} \mathrm{~g}^{-1}(0.2 \mathrm{C})$. (d) Cyclability rate of the HCNP-1150 electrode at different discharge/charge current densities of 25 (0.1 C), 50 (0.2 C), 125 (0.5 C), $250(1 \mathrm{C}), 1250(5 \mathrm{C})$ and $2500(10 \mathrm{C}) \mathrm{mAh} \mathrm{g}^{-1}$, respectively. 

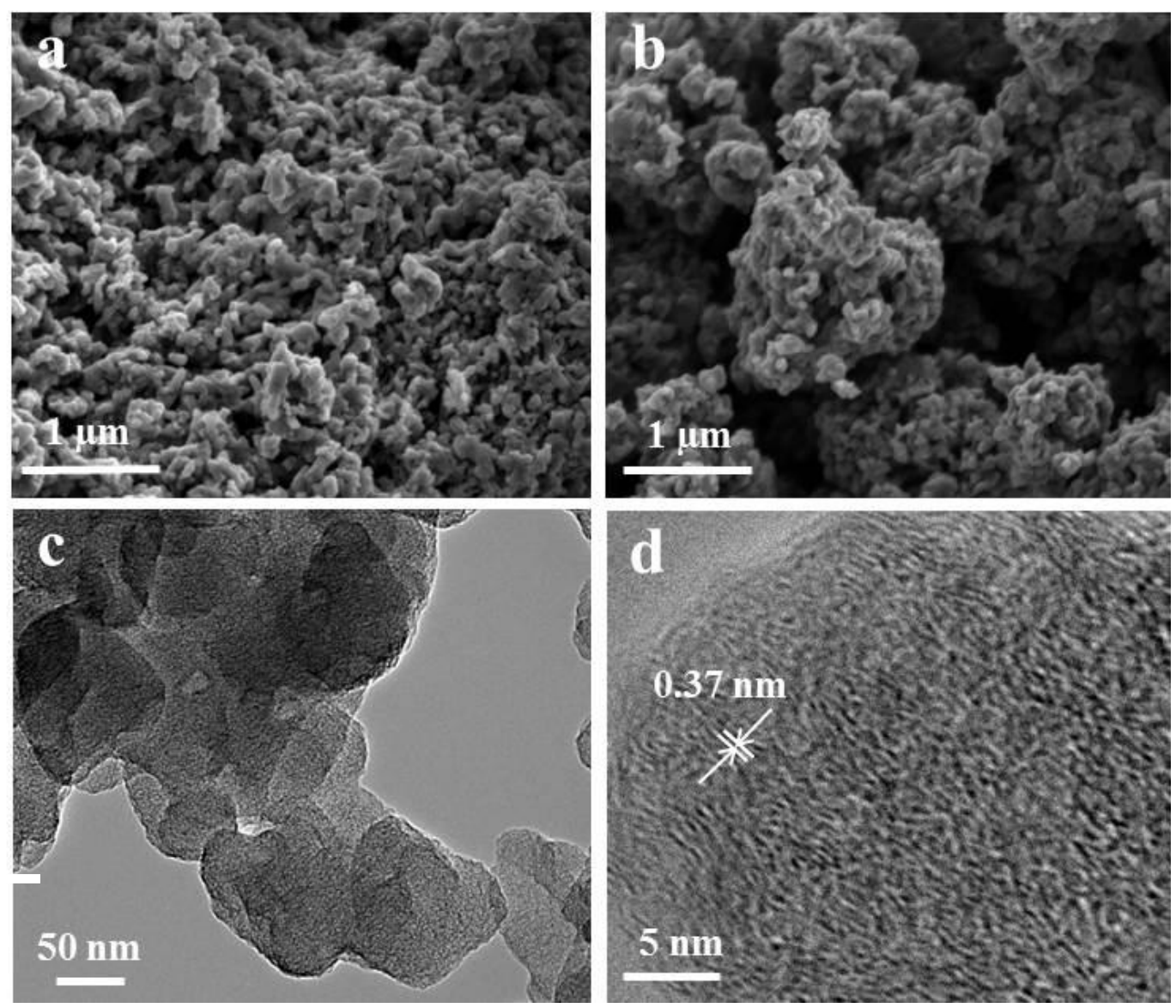

Fig. 1 

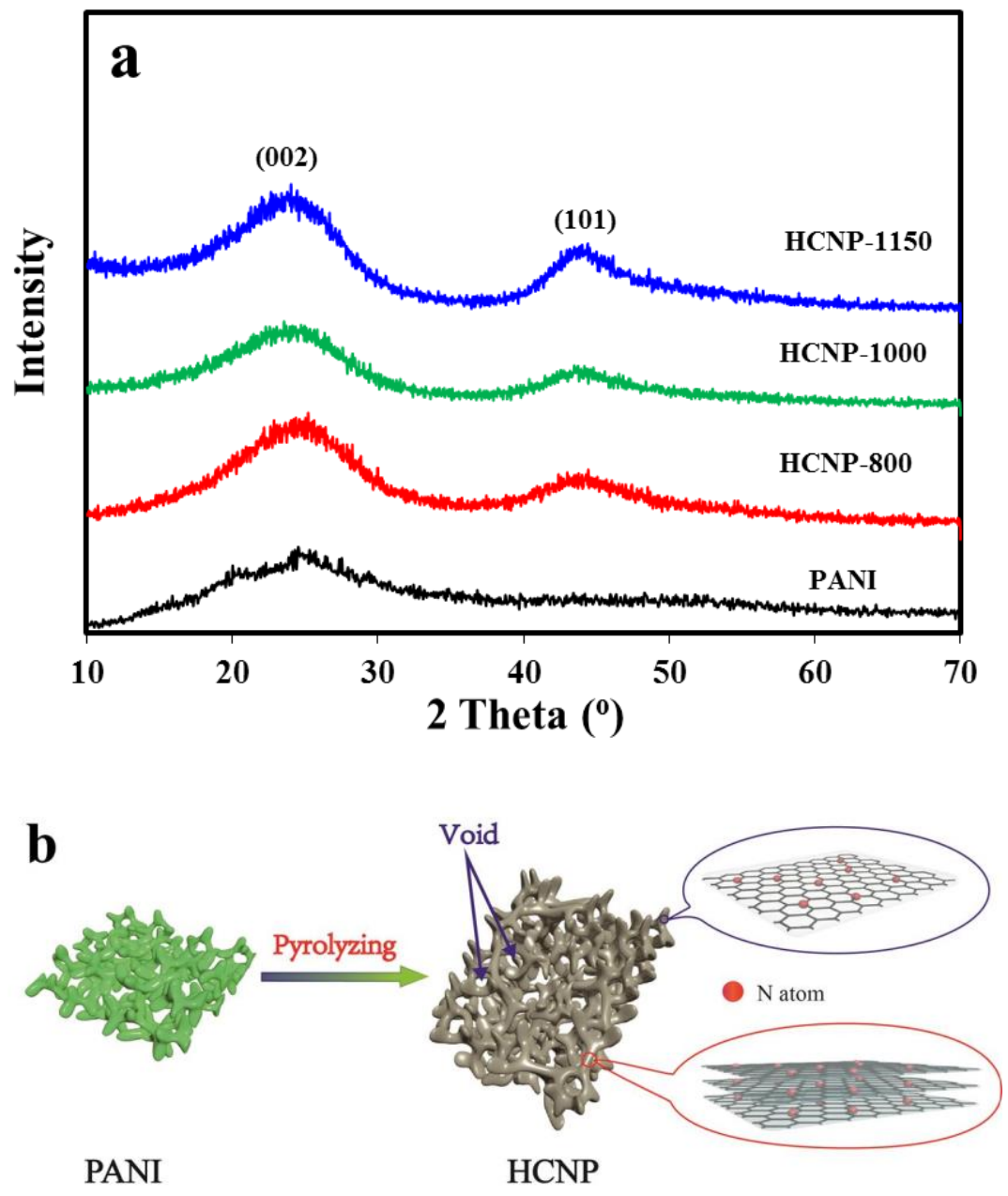

Fig. 2 

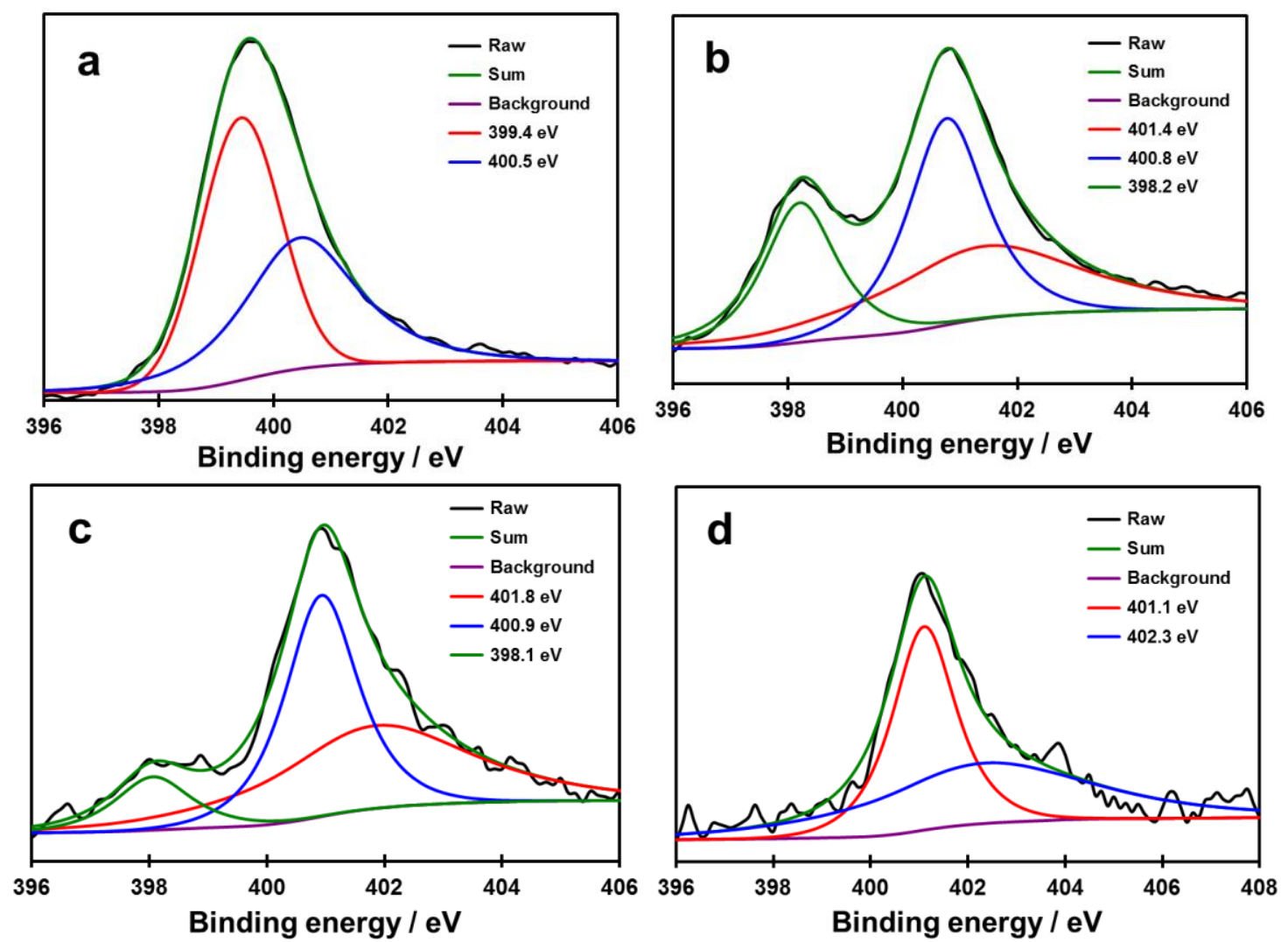

Fig. 3 

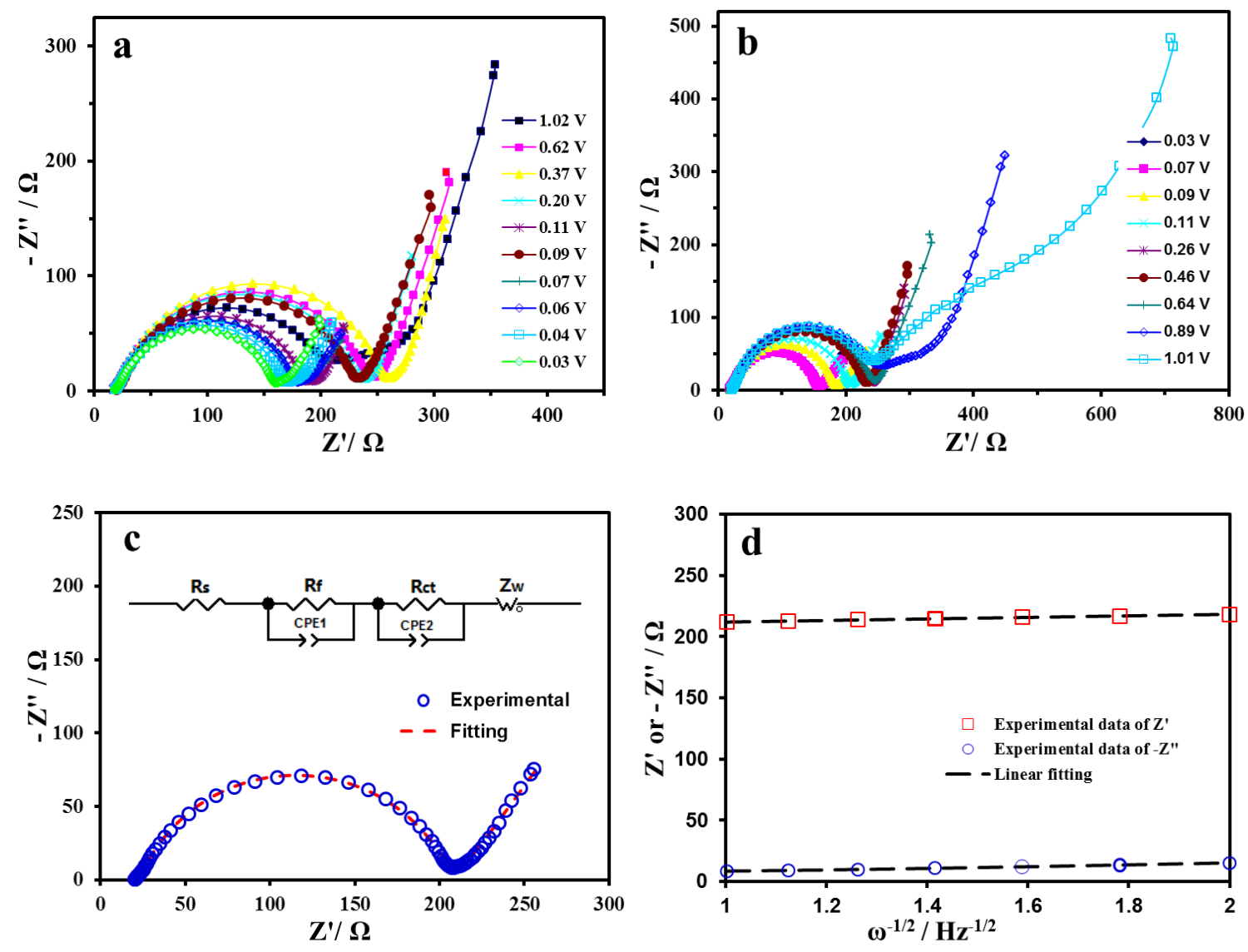

Fig. 4 


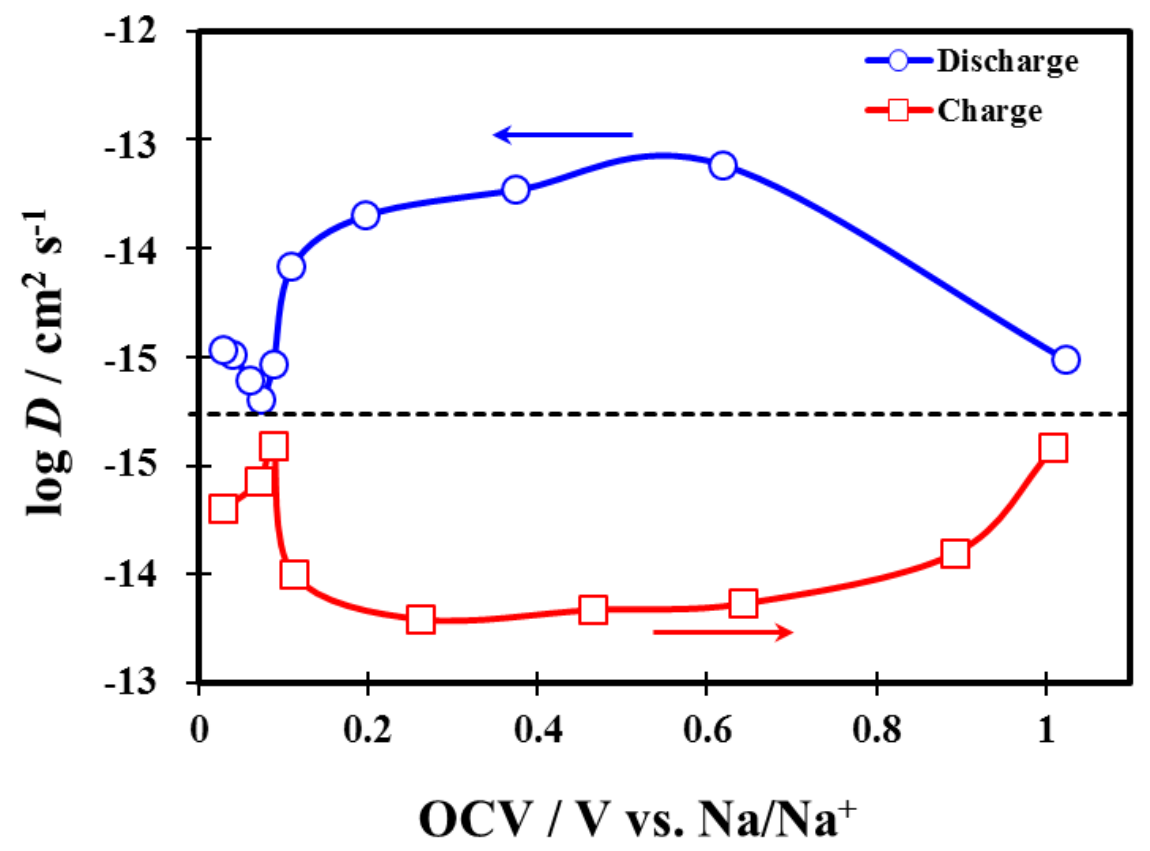

Fig. 5 

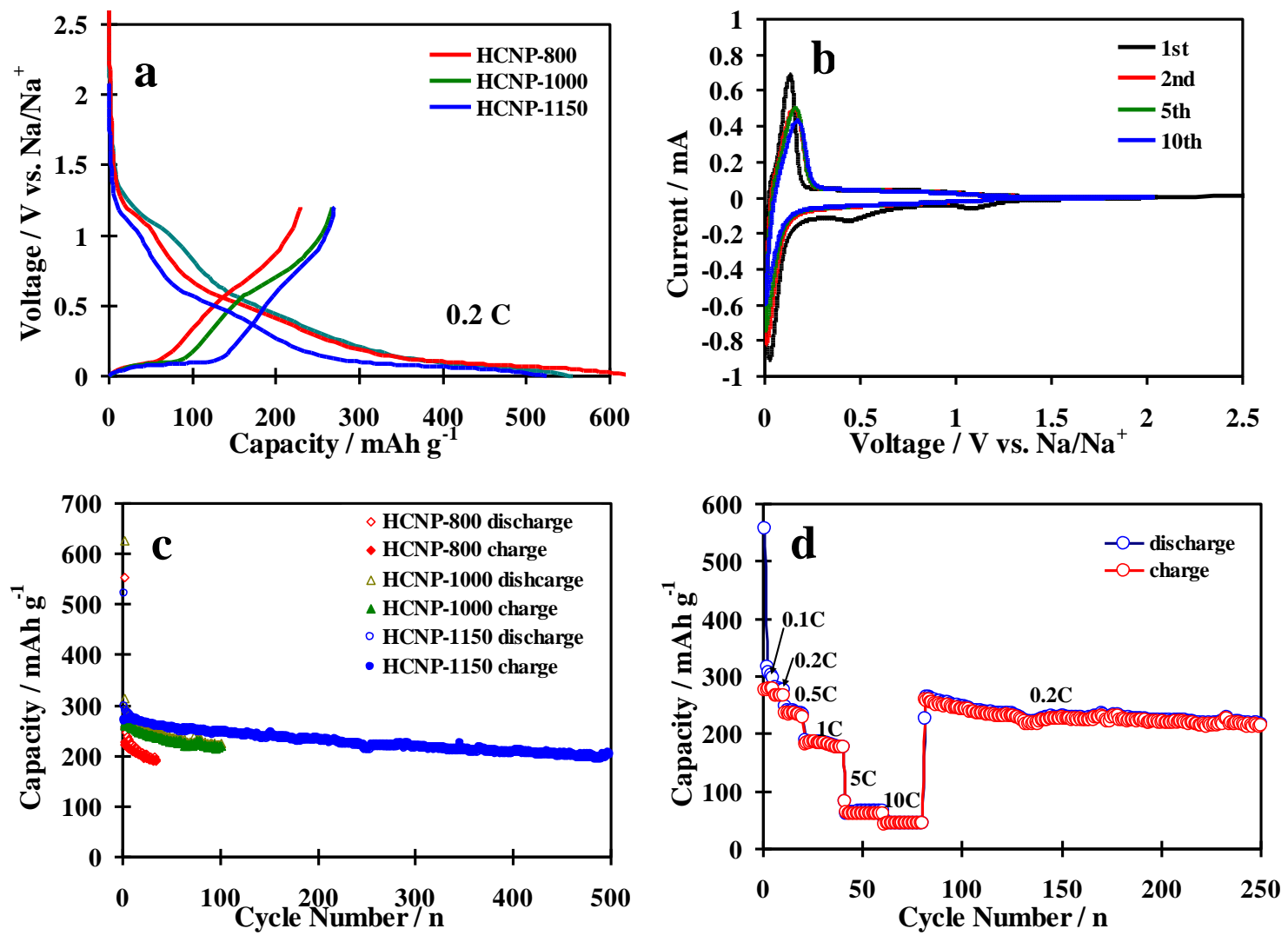

Fig. 6 


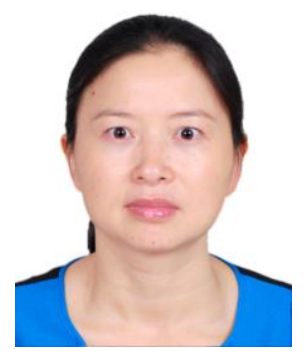

Dr. Lifen Xiao received her Ph.D. in Physical Chemistry from Wuhan University of China in 2003. She worked at College of Chemistry in Central China Normal University and now as a visiting scholar at Pacific Northwest National Laboratory. Her research is focused on novel electrode materials for electrochemical energy conversion and storage.

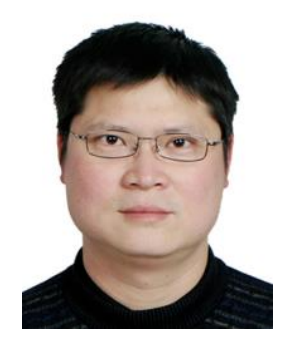

Dr. Yuliang Cao received his bachelor' degree (1997) and Ph.D. (2003) in Wuhan University, China, and then he worked as a professor in Wuhan University and worked as a visiting scholar in Pacific Northwest National Laboratory from 2010 to 2012. His research interest mainly focuses on alloy nanocomposite anodes, transitionmetal oxide cathodes and novel electrolytes for sodium ion batteries.

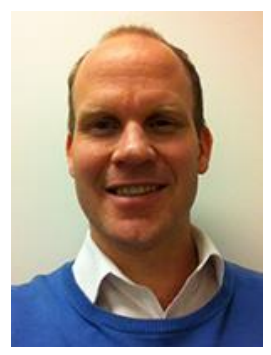

Dr. Wesley Henderson received his B.S. degree in Chemistry from UC Santa Barbara in 1996 and his Ph.D. in Materials Science \& Engineering from the University of Minnesota in 2002. He has worked as a researcher at Lawrence Berkeley National Laboratory (LBL) and Los Alamos National Laboratory (LANL) in the U.S., as well as at ENEA in Italy. He was an Associate Professor of Chemical Engineering at North Carolina State University before joining Pacific Northwest National Laboratory (PNNL) as a Senior Research Scientist in 2014. His research interests include the formulation of advanced electrolytes for energy storage/conversion applications.

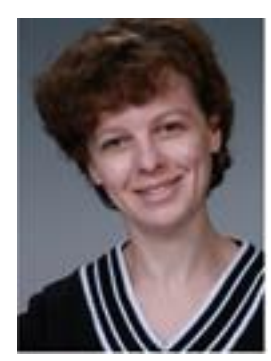

Dr. Maria Sushko is a Senior Scientist at Pacific Northwest National Laboratory. Before joining PNNL she worked at Imperial College London and University College London. She obtained her Ph.D. in Physics at the Institute of Macromolecular Compounds, Russian Academy of Science, St. Petersburg in 2000, where she studied selforganization in polymer solutions. Her current research is focused on the development of new computational tools for simulating nanoscale and mesoscale phenomena including self-assembly, nucleation, crystal growth, and ion and electron transport in nanocomposite materials.

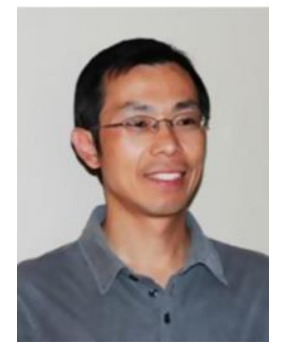

Dr. Yuyan Shao received his Ph.D. from Harbin Institute of Technology. He is a Senior Scientist the US DOE Pacific Northwest National Laboratory. His research is focused on the fundamental study and high performance functional materials for electrochemical energy conversion and storage, including fuel cells, batteries, supercapacitors, etc. He is named in Thomson Reuters' Highly Cited Researchers-2014. He has published over 90 papers. 


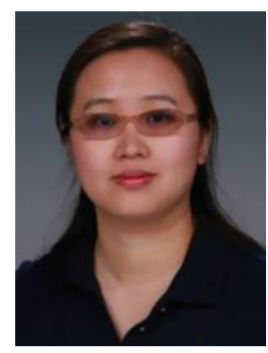

Dr. Jie Xiao is currently a senior staff scientist at PNNL. Dr. Xiao has been working in the energy research field for more than ten years. Of particular interest is the identification of new materials and novel technologies for energy storage and conversion. She is the recipient of several awards including Ronald L. Brodzinski Early Career Exceptional Achievement Award, two R\&D 100 awards and Zapperd Award from the American Chemical Society (ACS) etc. Dr. Xiao has published more than 70 peer-reviewed journal papers, 2 book chapters and filed 17 US patents (issued and pending) in energy storage area.

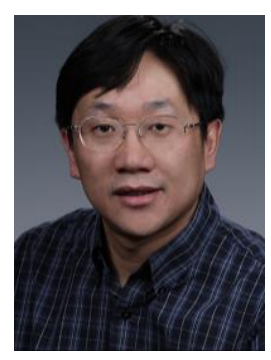

Dr. Wei Wang is a staff scientist at Pacific Northwest National Laboratory, where he is currently the technic lead on the research and development of redox flow battery technology. He has pioneered the development of several new redox flow battery technologies with multiple successful commercialization cases, for which he has been awarded an R\&D 100 Award, two FLC Awards, and 2012 PNNL Ronald L. Brodzinski Award for Early Career Exceptional Achievement. Dr. Wang has published over 50 peer-reviewed papers and three book chapters. He also holds four patents with multiple patent applications. Dr. Wang received his Ph.D in materials science and engineering from Carnegie Mellon University in 2009.

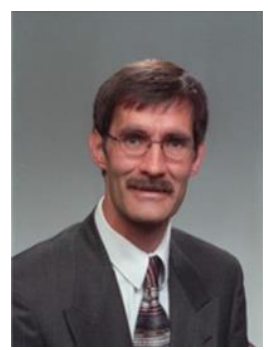

Dr. Mark Engelhard is a Senior Research Scientist at the Environmental and Molecular Sciences Laboratory (EMSL) operated by the Pacific Northwest National Laboratory (PNNL) located in Richland WA. As principal investigator, and project manager on various research projects funded by governmental and industrial clients, Engelhard has managed and coordinated scientific collaborations involving the application of surface analysis techniques. Engelhard was elected Fellow of the AVS Science and Technology Society in 2013. Mark's work is reported in over 350 peer-reviewed scientific publications and three book chapters. His papers have been cited more than $10 \mathrm{~K}$ times and his $h$-index is currently 56 .

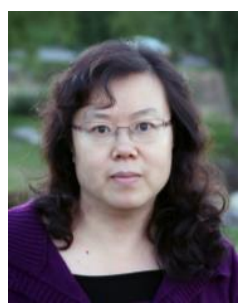

Zimin Nie is a Senior Research Scientist at PNNL. She has over 20 years' experience in synthesis of inorganic materials, energy materials and in materials composition and structural characterization using wide range of analytical tools including ICP, XRD, BET, UV-vis and HPLC. She has been actively engaged in the development of new redox flow batteries, and has received a Federal Laboratory Consortium Award for Technology Transfer. She has over 100 authored and co-authored papers. 


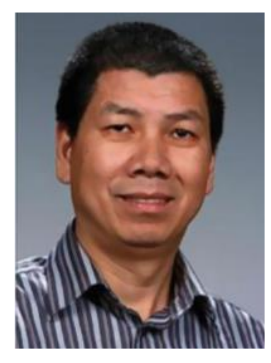

Dr. Jun Liu received his Ph.D.in materials science from University of Washington. He is a Laboratory Fellow and Energy Processes and Materials Division Director at the PNNL. His main research interest includes synthesis of functional nanomaterials for energy storage, catalysis, environmental separation and health care. He has received more than 55 U.S. patents, two R\&D 100 Awards, two BES Awards for Significant Impact on DOE Missions, and was named 2007 Distinguished Inventor of Battelle and Pacific Northwest national Laboratory Inventor of the Year in 2013. He is a Fellow for the Materials Research Society (MRS) and a Fellow for the American Association for Advancement of Science (AAAS). He is named in Thomson Reuters' Highly Cited Researchers 2014 and 2015. 
MS Title: Hard Carbon Nanoparticles as High-capacity, High-stability Anodic Materials for Na-ion Batteries

Authors: Lifen Xiao, Yuliang Cao,*, Wesley A. Henderson, Maria L. Sushko, Yuyan Shao, Jie Xiao, Wei Wang, Mark H. Engelhard, Zimin Nie, Jun Liu*

\section{Graphical Abstract}

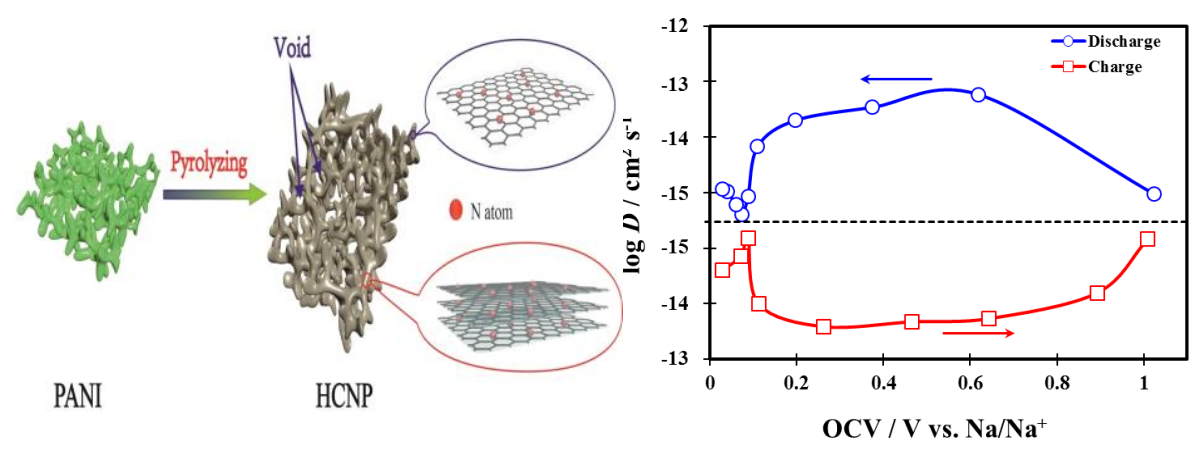

Hard carbon nanoparticles (HCNPs) synthesized by the pyrolysis of a polyaniline precursor display an optimum electrochemical performance. Particularly, the first measurements of the $\mathrm{Na}$ cations diffusion variation throughout the insertion/extraction processes in HCNP provide helpful insight into the stepwise Na cation insertion/extraction phases and rates in hard carbon materials. 